\title{
MORPHOSYNTACTIC MISMATCHES REVISITED: THE CASE OF THE ROMANIAN SUPINE
}

\section{ELENA SOARE}

\author{
UFR Sciences du Langage \\ Université de Paris 8 \\ 2 , rue de la Liberté \\ 93526-Saint-Denis cedex 02 \\ France \\ elena@linguist.jussieu.fr
}

\begin{abstract}
This article proposes a general survey of a supposed mixed category in Romanian, namely the supine. It is shown that what seems to be a mixed verbal-nominal nature is a context-dependent behaviour, determined by syntactic categories that may select a supine form. The core argument is that the two behaviours are associated with different projections. These facts are naturally captured by the theoretical framework of Distributed Morphology. Three forms of Romanian grammar are derived from the same underspecified item, which is a categorially neutral stem feeding derivational and inflectional processes. Arguments are provided from the behaviour of forms which involve the same stem: nominalizations and past participles.
\end{abstract}

Keywords: morphosyntactic mismatches, mixed categories, participial stem, underspecification, Distributed Morphology

The boundary between inflectional and derivational processes is not always clear. Moreover, sometimes word-formation and inflection are using the same material and the same operations. In some cases, this results in various sorts of mismatches: inflectional (cf. the fact that a form like a participle can project a full VP like in he kept [VP-prp putting PRP $_{\text {the book }}$ behind the couch]) and categorial mismatches (cf. the double categorization of the English gerund in the structure called "poss-ing").

This presentation is concerned with morphosyntactic mismatches, i.e., mismatches between features that count for the external syntax (distribution) and features that count for the internal syntax. Such cases 
are the English "poss-ing" gerund or the Romanian supine, which will be our main concern.

This last form brings an interesting case into that picture. Among other syntactic uses, it has one which is a nominalized participle (by a process like "conversion"). This form is clearly used in derivational as well as in inflectional processes, and in this respect, it represents evidence in favor of approaches that try to unify inflectional and categorial mismatches.

So, we will try to take a look at the dual/mixed nature of the supine; determine its relationships with other parts of the system (inflectional and derivational aspects), and find the appropriate framework to fit the facts.

\section{What is Romanian supine?}

\subsection{The core facts about Romanian supine}

There are two major syntactic uses of the perfect participle crosslinguistically: (a) perfect verb formation (+ HAVE); (b) passive verb formation $(+\mathrm{BE}) .^{1}$

Romanian has a third use of the perfect participle: the "supine". The form of past participle in Romanian is used in three types of syntactic environments: nominal, adjectival and verbal. There is, on the one hand, a past participle, with verbal and adjectival uses:

(1) (a) am cules căpşuni

have picked strawberries

'I have picked strawberries'

(b) căpşunile sînt culese

strawberries-the are picked-agr

'The strawberries are picked'

On the other hand, traditional grammars take some of the contexts of the Romanian participle (preceded by prepositions) to involve a distinct form of the verbal paradigm, called supine, considered to have a mixed $[+\mathrm{N},+\mathrm{V}]$ nature (cf. (2)-(4)). In (2), the participial form appears in a

${ }^{1}$ Nothing special will be said about the mapping from "participle" to "adjective" (a case of automatic "inflectional mismatch"). We could assume, following Baker (2003), that the participle is in fact "the verbal adjective". 
nominal structure, in combination with a definite determiner, and the complement is assigned genitive case. In (3), the supine follows an aspectual auxiliary, expressing the end of an activity; in this case, it does not take an article, and requires the presence of a marker, a functional "preposition", de. In (4), the supine (expressing the Goal) is preceded by a subcategorized preposition in the complement position of a verb of motion.

(A) nominal supine: $D^{0}+$ participle:

(2) culesul căpşunilor

picking-the strawberries-gen

'strawberry picking'

(B) verbal supine: preposition + participle $^{2}$

$\mathrm{B} 1$ participle without $\mathrm{D}^{0}$, obligatorily preceded by the "preposition" de:

(3) am terminat de cules căpşunile

have finished to pick strawberries-the

'I have finished picking the strawberries'

B2 participle without $\mathrm{D}^{0}$, preceded by a subcategorized preposition:

(4) mergem la cules de căpşuni

go-1pl to picking of strawberries

'We are going to pick strawberries'

Let us have a brief look at non-finite forms in Romanian. The emboldened endings are meant to show how these are derived. The infinitive is the root (ending in the thematic vowel, $a / e / e a / i / \hat{\imath}$ ) eventually preceded by a particle $a$, expressing non-finite tense in Romanian (the infinitive is involved in the formation of the future). Tentatively, we may assume that infinitive is imperfective Asp, whereas participle is perfective Asp.

Table 1

Non-finite forms in Romanian

\begin{tabular}{llll}
\hline Infinitive & (a) cînta 'sing' & (a) citi 'read' & (a) merge 'walk' \\
Pres. part. & cîntînd 'singing' & citind 'reading' & $\begin{array}{l}\text { mergînd 'walking' } \\
\text { Past part. }\end{array}$ \\
cîntat 'sung' & citit 'read' & mers 'walked' \\
\hline
\end{tabular}

2 The examples illustrate the supine as complement to aspectual verbs. The same form appears in copular structures, reduced relatives, Tough constructions, i.e., in predicative contexts involving (small) clauses in other languages. 
There is no (morphological) reason to separate the "supine" from the "participle", as shown by the fact that the irregularities are exactly the same for the two cases, cf. the "sigmatic" participles mers, cules.

(5) cînta - cîntat - de cîntat / cîntatul

sing - sung - to sing / the singing

citi - citit - de citit / cititul

read - red - to read / the reading

culege - cules - de cules / culesul (*culegut)

pick - picked - to pick / the picking

merge - mers - de mers / mersul (*mergut)

walk - walked - to walk / the walking

\subsection{The problem}

We have some theoretical puzzles facing us in the Romanian supine. First, what kind of mismatches can we identify? Should we analyze the supine as a verbal noun, i.e., a mixed category? And, from a purely morphological point of view, what status should be assigned to the "participial morpheme", in our case AT (or Thematic Vowel + T)?

\section{Mixed or underspecified?}

\subsection{A mixed-category criterion: co-occurrence of different properties}

In the generative literature, some verbal nouns have been analyzed as "mixed categories" $(+\mathrm{N},+\mathrm{V})$, for instance the Arabic masdar (Fassi Fehri 1991), the Welsh verbal noun (Rouveret 1993) as well as the English gerund. Is the supine also a verbal noun?

A criterion for the mixed character is to find properties of two kinds of projections in the same projection, at the same time. For instance, the distribution would be nominal, as for the English gerund, which can appear in contexts excluded by non-nominal projections:

(6) (a) we were concerned about Pat's watching television

(b) * we were concerned about that Pat was watching television

The same type of projection is characterized by internal properties specific for verbs, i.e., accusative case assignment (7a-b) and adverbial modification (7c):

Acta Linguistica Hungarica 54, 2007 
(7) (a) John's building a spaceship

(b) I disapproved of Pat's watching television

(c) Pat disapproved of my * quiet / quietly leaving before anyone noticed

(d) *Pat disapproved that leaving

In $(8 \mathrm{a}-\mathrm{d})$, we give some other examples of mixed categories, manifesting a "griffon" behavior: a verbal head with hybrid properties - nominalized infinitives in Italian (8a), Spanish (8b) and Old Romanian (8c); Arabic masdar (which in fact has more complex properties) is illustrated in (8d):

(8) (a) il rivedere un compagno d'armi

the see-again a companion of arms

'the fact of seeing again a brother in arms'

(b) el haber-me-lo dicho

the have-me-it said

'the fact that he told it to me'

(c) tăierea capul lui

cutting-the head-the him

'the fact of cutting his head'

(d) quatl-u Zayd-in Muhammad-an murder-nom Zayd-gen Muhammad-acc 'the murder of Muhammad by Zayd'

The behavior of the Romanian supine does not respect the mixedbehavior criterion; instead of showing hybrid properties at the same time, its verbal/nominal nature (or "ambiguity", according to traditional grammars) is manifested as contextually dependent. And indeed, we see that the supine combined with a determiner fails to assign accusative or nominative case. Its projection is completely reorganized according to the nominal pattern:

(9) (a) *culesul căpşuni

picking-the strawberry

'strawberry picking'

(b) *culesul Ion

picking-the Ion

'Ion's picking'

The problem in these examples is the fact that the arguments are not assigned case, which in Romanian corresponds either to morphological 
case or to the insertion of a "preposition". The problem disappears when the internal argument has the form of an NP in the genitive or that of a PP adjunct:

(10) (a) culesul căpşunilor

picking-det strawberries-gen

'the picking of strawberries'

(b) culesul de căpşuni

picking-det of strawberries

'the picking of strawberries'

Moreover, case licensing of the object does not seem to be a property of the supine form in itself. The possibility to assign strong accusative case appears only if there is more verbal structure around. This is the case for (11a), in which the supine combines with an auxiliary verb.

(11) (a) am de cules căpşuni

have to pick strawberries

'I have to pick strawberries'

(b) *cules căpşuni (e o activitate plăcută)

pick strawberries (is a pleasant activity)

'picking strawberries is a pleasant activity'

This observation leads to the idea that the supine itself cannot assign a case to its complements. In the case of the nominal projection, this is done by the presence of nominal determination. Within the verbal projection, the supine combines with auxiliaries, forming a verbal complex, which, as a whole, is responsible for case-licensing of the complements. The result is not a "mixed" projection because the different properties of the supine are not manifested at the same time, in the same projection, but in different projections.

Another possibility would be to say that the auxiliary assigns an "aspectual role" to this object, and contributes to fully identifying it, and that the supine only assigns a weak case to this object. This way of analysis was proposed for the Scottish Gaelic verbal noun by Ramchand (1997), who considers that this characteristic is due to the nominal status of this verbal noun.

We therefore retain as a conclusion the following idea: the supine changes its projection type as it changes its morphological properties; it does not match the mixed-category criterion.

Acta Linguistica Hungarica 54, 2007 
There is an apparent exception to this generalization, represented by the supine inside a PP projection, in which the preposition is selected by the main verb or has an autonomous lexical meaning (such as Goal), in the case of adjuncts. In traditional grammars, this prepositional supine is considered to be verbal (accusative-case assigner). This is the essential argument of traditional grammars in saying that the supine keeps its verbal properties in this kind of contexts.

(12) am plecat la cules căpşuni

have gone at picking strawberries

'I'm going to pick strawberries'

On the basis of this type of examples, traditional grammars take the view that the supine is a case-assigner when it is introduced by a preposition. We have to note that these cases are restricted to supine expressing Goal. Also, when the supine is preceded by lexical sub-categorized prepositions, the prepositional accusative becomes impossible for the object of that supine. The strong structural accusative case is not allowed:

(13)*am renunțat la invitat pe Ion / pe acest om

have renounced to invite $p e$-acc Ion / pe-acc this man

'I renounced to invite Ion / this man'

This is even more striking if we compare the supine with another nonfinite form of the Romanian verbal system, the infinitive, which is perfectly compatible with prepositional accusative case:

(14) am renunțat la a invita pe Ion / pe acest om

have renounced to invite $p e$-acc Ion / pe-acc this man

'I renounced to invite Ion / this man'

Another important remark is that in prepositional contexts, the object is always strictly adjacent and non-determined, whereas in ordinary verbal constructions, the object allows determination, quantification etc., and can be separated from the verb by temporal modifiers:

(15) (a) *am plecat la cules multe căpşuni / toate căpşunile have gone to pick many strawberries / all strawberries-the 'I am going to pick many strawberries / all the strawberries'

(b) *am plecat la cules imediat căpşuni have gone to pick immediately strawberries 'I am going to pick strawberries immediately' 
Therefore, it seems that a direct object in such supine constructions manifests a special behavior, to be distinguished from the regular behavior of a direct object in an ordinary verbal construction. The only "objects" allowed by the supine in the absence of an auxiliary are bare, predicative NPs (not DPs), which do not accept strong accusative case. What they bear is a weak case, that may appear with defective forms (quasi-nominal, or uncategorized forms; see also in this sense Ramchand's (1997) proposal for the Scottish Gaelic VN). Another explanation that could be adopted is that this behavior is due to the fact that the structure is frozen, and relies probably on a composition of the type $\mathrm{N}-\mathrm{N}$, generated by lexical rules (as compounds). If this is true, structures like (12), with PPs containing supines, involve nominal supine compound structures, in which the "light" object enters in a lexical compounding relation to the supine. An argument in this sense is given by the existence of structures of the type in (16), appearing in enumerations or other particular contexts (titles, labels), where the model of composition is possible with participles:

(16) n-am uitat nimic: cumpărat bilete, făcut bagaje...

not have forget anything: buying tickets, packing bags

'I didn't forget anything: buying tickets, packing bags...'

Moreover, present-day Romanian tends to favor the construction with de-insertion instead of the direct one with the presumed accusative object. Therefore, the perspective offered by productive supine structures is that of an element whose verbal-nominal nature is not "double" or "mixed", but clearly context-dependent, distinguishing this form from "true" verbal nouns.

\subsection{Capturing mismatches}

There is a recognized difference between lexicalist and non-lexicalist approaches with respect to the treatment of inflectional mismatches versus category mismatches. Lexicalist approaches treat them as completely different, whereas non-lexicalist approaches treat them alike, via a HeadMovement-type analysis. 


\subsubsection{Lexicalist approaches}

Feature-percolation systems (Head feature principle) account for the transmission of morphological features, e.g., "participle", from the head to the maximal phrase:

(17)

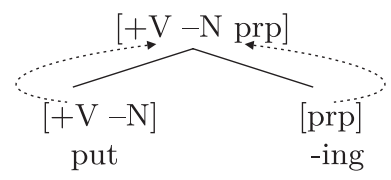

In the case of mixed categories, this system would result in contradictory feature specifications:

(18)

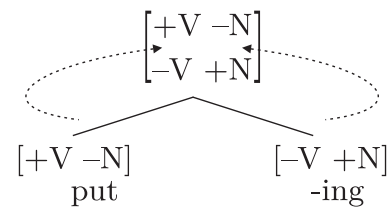

A lexicalist solution for mixed-type of mismatch (English gerund) would propose:

- a "split-head" analysis of the type of Lapointe's (1993; 1999) Dual Lexical Categories:

(19)

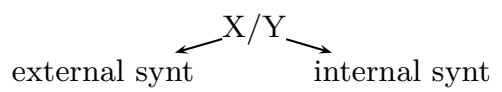

- a "mixed-head" analysis of the type of Malouf's (1998) Hierarchical Lexicon:

(20)

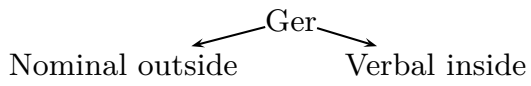

The main idea of this type of framework is that the items at hand are doubly categorized items and that there is feature percolation from the base categories to the resulting category. Roots bear POS specifications. 
The inflectional and categorial mismatches are not alike (more precisely, there is no inflectional mismatch).

There have also been attempts to unify inflectional and category mismatches, based on the argument that features contributed by inflectional affixes are exclusively relevant for external syntax (Yoon 2005). This was also the sense of Haspelmath's (1995) proposal that inflection should also cover word-class changing relations, i.e., transpositional inflection: word-class changing inflections are special cases of inflection in his view. Another attempt was to say that features contributed by inflectional affixes are exclusively relevant for external syntax (Yoon 2005). The result is that inflectional and category mismatches are treated alike.

\subsubsection{Non-lexicalist approaches}

A syntactic view would more or less say that the head affix would move and incorporate, giving rise to categories accumulating features all the way up, like in current generative models since the late '80s (from Abney 1987 to Alexiadou 2001).

This is the option adopted by Distributed Morphology (Marantz 1997; Harley-Noyer 1998). In this theoretical framework, the items listed in the vocabulary have no category, categorization being contributed by the syntactic component. The insertion of an element in the appropriate syntactic context makes it a nominal, or verbal, or adjectival... element.

In the vision of syntactic approaches then, inflectional and derivational mismatches are assigned a unified treatment; categories are built up by operations of head-movement and incorporation of affixes; there is no POS specification on Roots.

Word formation involves Root derivation:

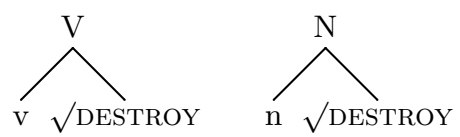

A Root $=$ an l-morpheme; a Noun $=$ a Root whose nearest c-commanding element is a $\mathrm{D}^{0}$; a Verb $=\mathrm{a}$ Root whose nearest licenser is Aspect or Tense

In the appropriate context, a Root becomes a Noun, a Verb... via the combination with an f-morpheme: $\mathrm{n}, \mathrm{v}$...

There is a clear connection between syntactic behavior and categorization. Lexical categories, heads of syntactic projections, determine the internal structure of the projection (selection, projection, complement li- 
censing), and the type of position in which the corresponding phrases will be inserted, as well.

For the case of the supine, there are empirical facts that contribute to an "underspecification"-type analysis, as we tried to show in section 2.1.

\subsection{What kind of mismatch in the supine?}

Is the type of mismatch manifested in the Romanian supine purely inflectional? The answer is no: we do not find a morphological process that is "relevant to syntax"; the -at form does not determine the global behavior and the functional nodes, inasmuch as it can feed a nominal or a verbal structure. Then, the process of making a participle from a verb is not clearly category-neutral. There are researchers who proposed that the participial morpheme is a derivational affix (Schütze 2003, for instance).

Is it purely derivational then? The answer is again no: we do not clearly obtain different "lexemes" by the process of supine formation.

However, if we see inflection and derivation as a continuum, we may think about the corresponding mismatches as being alike: neutral l-morphemes combined with f-morphemes which can compete for different values. In the case of gerund, for instance (Harley-Noyer 1998), the -ing suffix can be analyzed as a default nominalizer; it would then be a $\mathbf{n}$ or a $\mathbf{v}$ head according to what we find in higher structure (Asp or Det).

\subsection{Distributed Morphology-style treatment of the supine/participle}

If our view is correct, an analysis that seems to impose itself is the "underspecification" analysis, proposed in the Distributed Morphology framework. The participle has no categorial features, being categorized by the syntactic context.

We can then propose the following supine-formation system (DMstyle):

(22)
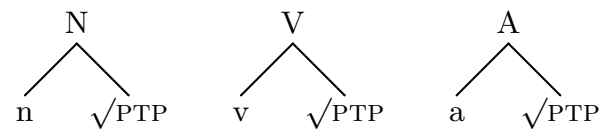

According to the view of Distributed Morphology, there are no categorial features at the "Vocabulary" level. Participle would then be a single uncategorized item competing for several syntactic contexts. 
At this point, we could ask the following question: should we talk only about uncategorized roots or about uncategorized stems? If PTP is a root, then what is the infinitive?

What is less clear indeed, is which label to put on the participial form itself. In DM, there are category-neutral "roots" (l-morphemes), and there are affixes with features competing for a specific value to express (f-morphemes). The analysis we would like to propose is that the participle, PTP, is itself category-less. Or, it is not really a root, being composed of a verbal root and the participial affix. We shall try now to find a solution to this puzzle.

\section{Emergence of a Latin-type "third stem" in Romanian?}

Many modern theoretical views are consistent with the existence of an uncategorial level of grammatical representation. Baker (2003), for instance, considers that category is given by syntax. The categorial identification is done by the syntax in the following way: a Noun - has a referential index; a Verb - has a specifier; an Adjective-by default is - N, -V. In his system, however, the participle is not really discussed; it is considered a "verbal adjective" without further investigation.

Schütze (2003) takes the participial suffix as being category-changing, creating participles from verbs. This makes them derivational affixes. As for the participle, it is considered as not being (really) a verb; it does not carry voice, but only (lexical?) aspect. So, the participle is a decategorized verb. This, however, takes in fact the participle to be a distinct category.

Aronoff (1994) discusses the problem of (English) participle, which, according to him, illustrates the "morphomic" level; being purely morphological, this element is appropriate for the very different syntactic constructions of past and passive.

Another argument for the "morphomic" level discussed by Aronoff (1994) is the existence of the Latin "third stem", realized in participle, supine, and future active participle. In this case, a single stem, also a "morpheme", is used in various syntactic environments. The supine was a verbal noun; derived from a participial stem (from a synchronic point of view), it was an item that allowed nominal inflection (case marking) and appeared as Goal adjunct with verbs or adjectives: 
(23) (a) eo lusum

go playing

(b) mirabile visu

wonderful to see

The argument in favor of a verbal noun analysis comes from the possibility of case marking on the direct object by the supine, and the co-occurrence of the nominal inflection on it. According to Aronoff (1994), the supine should be treated as the manifestation of the same Stem (in the strict morphological sense, at the "morphomic" level) as that of the participle, even if the values (aspect, voice) of the categories derived from this stem are different (the supine does not admit the passive interpretation in Latin). The same stem is used to derive a number of deverbal nouns in Latin, such as pictura, derived from pingo, pict-. Aronoff (ibid.) builds in this way an argument for the view that the morphological level should be kept distinct from syntax, semantic or phonology; morphemes do not encode (grammatical) meaning since, in the cases illustrated, they do not always have the same value.

Indeed, the same thematic element appears in very different formations, like the active future participle, meaning "those which will V" and in the supine, denoting the activity without further specifications, and in the past participle, denoting a state, a result.

\section{(24) Active Future Participle}

mor-it-uri te salutant

die-th-fut.part you salute

'Those going to die salute you'

(25) Supine

(a) eo pisc-at-um

go1sg fish-th-acc

'I go fishing'

(b) pingo, pict- $\rightarrow$ pict-ura

I paint painting

It could also be interesting to note that, putting aside any attempt to diachronically explain the existence of the Romanian supine (in other words, the extended use of the participial stem), Romanian supine and Latin supine present rather similar distributions, i.e., the expressing of the goal or of the point of view. 
We are not able to propose, at this moment, an analysis for both Latin and Romanian, but we may simply retain Aronoff's suggestion for Romanian, that there is a single stem at work in the two cases. This stem can be used as a base as well for verb as for noun formation. In sum, none of these forms is basic; they are all derived from a single sound form - a stem.

Therefore, we would like to apply the same view to Romanian participle and supine, which, as we saw, are perfectly homophonous. The advantage would be that we would unify two categories of the non-finite verbal system of Romanian that seem to have all in common. But in this case, we would rather like to say that a single morphological element, categorially neutral, is used to build a noun (the supine), a verb (in combination with an auxiliary, see before), or an adjective. This is the analysis proposed above, and it goes somehow in the same direction as Aronoff's discussion.

One question to ask is whether Romanian morphology can be considered to be based on stems, and if the participle is a stem. Such a view could be supported by the fact that the $-A T$ formation is also used in derivation. $-A T$ can also attach to non-verbal roots:

(26) Root $+\mathrm{V} \rightarrow \mathrm{V}$-at (categorially neutral element)

mîncat 'eating', cîntat 'singing', citit 'reading', mers 'walking'

(27) Root $+\mathrm{N} \rightarrow[$ Adj] (state of someone who has...)

sprîncenat 'eye-browed', migdalat 'almond-ed'

- $A T$ could be considered also as participating in the derivation of agent nouns. The idea that it would be the realization of the same stem is however contradicted by the variation illustrated in $(28 \mathrm{~d}-\mathrm{e})$. However, the correspondence between the participle and the stem of agent nouns is stable for the "regular" classes of verbs $(28 \mathrm{a}-\mathrm{c})$.

(28) Root $+t+$-or $\rightarrow$ Agent Nouns
(a) cînta 'sing'-cîntăt-or 'singer'
(b) măguli 'flatter'-măgulit-or 'flatterer'
(c) hotărî 'decide'-hotărît-or 'decisive'
(d) merge 'walk'-mers-mergător 'walker'
(e) culege 'pick'-cules-culegător 'picker' 
There are, we think, reasons to treat the participial form as one of the stems of the verb in Romanian. It would be a rather particular use of this notion, which should be used for "what remains when all affixes are set apart". In our case, contrary to Latin, there are no affixes going with the nominal vs. verbal or adjectival status. ${ }^{3}$ But we could assign the status of a stem to the part which is common to all these syntactic uses mentioned above, and it would correspond to "what remains when the categorial features are set apart".

\section{Importing stems into Marantz's (1997) system?}

Let us sketch now a way of making sense of all the intuitions above. We will assume that the most qualified model accounting for the facts outlined in this paper is Distributed Morphology, as depicted in Marantz (1997). The only inconvenience would be that our participles seem to be at the same time basic and constructed.

In fact, the relationship between destruct and destroy, for instance, in this framework, is ensured by "readjustment rules". In our case, there seem to be not different instantiations/spell-outs of the same abstract ROOT, but indeed two roots - or two stems, if it is possible to talk about stems that are neutral from the point of view of syntactic category.

We assume that in Romanian there are perfective and imperfective neutral stems, i.e., participial and infinitive stems.

In the system proposed here, stems as neutral elements are combined with nominal, adjectival, verbal heads. In our case, that of the Romanian participle, these heads do not have phonological content. Put differently, we assume that the difference between Romanian participle/ supine formation and English gerund formation is that -ing is a nominal head, whereas -at is not. We illustrate hereafter the different types of word-formation corresponding to gerund and to supine; all of them take place in the syntactic component, according to the Distributed Morphology framework.

3 There are, of course, marks of agreement in gender and number when the participle is in an adjectival position, but no marks of declension for the supine use. 
(29) (a)

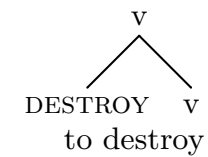

(c)

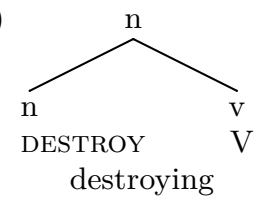

(b)

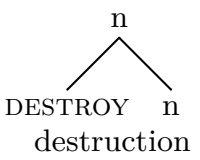

(d)

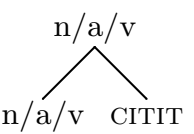

\section{Is $-A T$ ( simply) an empty morpheme?}

What is -at, then? The answer, in Aronoff's terms, would be that -at is an empty thematic morpheme, and we have already seen the arguments (section 2). We may have some arguments for taking this morphological piece as the expression of (lexical) Aspect. Participial stems, as we will argue below, encode Aspect. If this is correct, the view of Aronoff (1994) about the complete absence of semantic-grammatical value for the participial stem could be challenged, at least for the Romanian participle. The thematic affix (AT or Thematic Vowel $+\mathrm{T}$ ) seems to keep a certain value in Romanian, which we take to be an aspectual one.

We take the basic aspectual value of the participial stem to be a perfective one. This is indeed the default value of past participle constructions, as is well known.

This aspectual value of the participial stem will be changed by the contribution of various markers. The first one is the nominalizer element, i.e., the determiner. Event supine-based nominalizations, as shown by Cornilescu (1999; 2006), take an atelic reading most of the time. This is a consequence of the nominal status of the supine and of the weak status of the object. The supine nominal can take implicit arguments, and in particular implicit objects, hence its atelic value:

(30) cîntatul este un dar

singing-the is a gift

'singing is a gift'

However, those are contexts with a generic reading, the supine denotes a generic event, and the aspectual value is shifted to the iterative-habitual reading. 
The aspectual value attached to the participial stem that we supposed was present in agent -tor derived nouns is not clear, but in any case they seem to be atelic. In those examples, too, we could find an aspectual component which is habitual (someone has to perform an activity regularly in order to be, for instance, a dancer or a smoker).

In some periphrases, the participial stem is attached to the expression of completion, a value that has also to do with perfectivity. See for example (31), where the action of reading has to be completed, or the movement to reach its goal:

(31) (a) am de citit acest articol pînă mîine

have to read this article till tomorrow

'I have to read this article till tomorrow'

(b) am de mers la piață

have to go to market

'I have to go to the market place'

There are also event nominalizations in which a value of completion is encoded, in cases where the object is assigned strong genitive case.

(32) (a) cititul ziarului de dimineată

reading-the newspaper-gen of morning

'the reading of the newspaper in the morning'

(b) ?cititul de dimineață

reading-the of morning

'reading in the morning'

The partition that we suggested seems to be supported by the fact that the imperfective stem is used in some derived nouns but also in the future form. In Old Romanian, the so-called "long infinitive" which is nowadays a noun was used as an infinitive. In the same way, the participle is used in nominalizations and in complex (perfective) tenses.

(33) (a) mînca-re-a

eat-inf-suff-det

'the food'

(b) mîncat-ul

eat-sup-det

'the eating' 


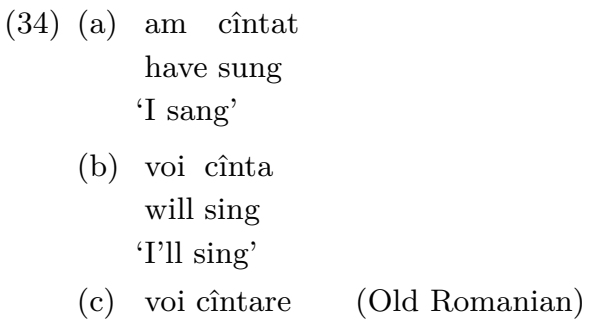

We may assume, then, that the supine/participle stem encodes Aspect; its basic value could be considered to be perfectivity. Some contexts, however, may involve shifting to an atelic iterative-habitual reading.

As for the Voice value of this stem, there is a discussion in the Romanian literature, about its voice ambiguity, which may go in the sense of Aronoff (1994): supine has been considered as ambiguous between active and passive reading. But in fact, supine's properties lead us to think that it is rather a non-active form (maybe a middle). Active reading is not possible unless the supine has nominal properties, i.e., in the prepositional context discussed above. In the other cases, if it does not have a clear passive reading (which holds for the supine reduced relatives), the active reading is associated with an arbitrary reading of the subject.

A suggestion that could be made with respect to the aspectual value of the perfective stem is that it may shift its aspectual nature according to the way of realizing its object (i.e., in the basic position inside or outside VP). For instance, in the past participle constructions, the object will be realized in its basic position and assigned strong structural accusative case, the whole construction Aux + Participle being able to case-mark it. In other constructions with the traditional supine, the object would only be assigned weak case, having a predicate-modifier status. The two options are associated with a telic and atelic aspectual value, respectively.

\section{Summary}

We argued in this paper that the participle, ROOT $+A T$ by itself is not $[+\mathrm{N}],[+\mathrm{V}]$. Participles need syntactic supporters - functional elements, i.e., auxiliaries or determiners, in order to receive a category. (Stative and resultative) participle, verbal "supine", "supine" event nouns in Romanian are all syntactic realizations of the "3rd stem". The AT-Stem (or PTP, or the 3rd stem) combines with different functional layers attributing categories: $a, n$ or v. AT itself is not $a, n$ or $v$. 
Stems are categorially neutral and accessible to inflection and to derivation. This leads to the triple use of the Romanian participle known as the past participle/supine parallelism in Romanian. The view of the grammar which could fit the facts discussed in this paper is the one outlined in Distributed Morphology, where "mixed categories" are not needed. In such a framework, it is possible to have an analysis in which a single morphological piece corresponds to three linguistic units. The only device we would have to add is that stems can also be categorially neutral and represent starting points in word formation.

\section{References}

Abney, Steven 1987. English NP in its sentential aspect. Doctoral dissertation, MIT. Alexiadou, Artemis 2001. Functional structure in nominals: Nominalization and ergativity. John Benjamins, Amsterdam \& Philadelphia.

Aronoff, Mark 1994. Morphology by itself. Stems and inflectional classes. MIT Press, Cambridge MA.

Baker, Mark C. 2003. Lexical categories. Verbs, nouns, adjectives. Cambridge University Press, Cambridge.

Cornilescu, Alexandra 1999. Aspect and nominalizations. The case of Romanian. In: István Kenesei (ed.): Crossing boundaries: Advances in the theory of Central and Eastern European languages, 211-38. John Benjamins, Amsterdam \& Philadelphia.

Cornilescu, Alexandra 2006. Nominalizations. Manuscript. (http://www.linguist.jussieu.fr)

Fassi Fehri, Abdelkader 1991. Arabic clauses and words. Kluwer, Dordrecht.

Harley, Heidi - Rolf Noyer 1998. Mixed nominalizations, short verb movement and object shift in English. In: NELS $28: 143-57$.

Haspelmath, Martin 1995. Word-class changing inflection and morphological theory. In: Geert Booij- Jaap van Marle (eds): Yearbook of morphology 1995, 43-66. Kluwer, Dordrecht.

Lapointe, Steve 1993. Dual lexical categories and the syntax of mixed category phrases. In: Andreas Kathol-Michael Bernstein (eds): Proceedings of the Eastern States Conference on Linguistics, 199-210. Cornell University, Ithaca NY.

Lapointe, Steven 1999. Dual lexical categories vs. phrasal conversion in the analysis of gerund phrases. In: Paul DeLacy - Anita Nowak (eds): University of Massachusetts Occasional Papers in Linguistics 24. Papers from the 25th anniversary, 157-89. GLSA, University of Massachusetts, Amherst.

Malouf, Rob 1998. Mixed categories in the hierarchical lexicon. Doctoral dissertation, Stanford University.

Marantz, Alec 1997. No escape from syntax: Don't try morphological analysis in the privacy of your own lexicon. In: University of Pennsylvania Working Papeprs in Linguistics $4: 201-25$. 
Ramchand, Gillian 1997. Aspect and predication. The semantics of argument structure. Oxford, Clarendon Press.

Rouveret, Alain 1993. Syntaxe du Gallois. Principes généraux et typologie. Editions du CNRS, Paris.

Schütze, Carson T. 2003. When is a verb not a verb? In: University of Troms $\varnothing$ Working Papers on Language and Linguistics 31. (http://www.ub.uit.no/munin/nordlyd)

Yoon, James H. 2005. Dual lexical categories and inflectional morphology. In: C. Orhan Orgun - Peter Sells (eds): Morphology and the web of grammar, 139-68. CSLI Publications, Stanford University. 